\title{
Efficient Sensorless Speed Control Approach using Comparator with Zero Cross Detection for Brushless DC Motor
}

\author{
B. Tamilselvi and S. Mumtaj
}

\begin{abstract}
Brushless DC Motor have used in various sectors like aerospace, manufacturing and home machines owing to its trouble-free construction. The exact information of the rotor position is necessary for better performance of brushless DC motors the need for the rotor angle information in BLDC has been fulfilled by make use of some form of rotor position sensor. In BLDC drives the position sensor contains drawbacks of high cost, electrical connections, mechanical position problems and disadvantage of being intrinsic source of irregularity. These restricted access results in several sensorless techniques in recent years. This paper provides sensorless speed control of Brushless DC motor using comparator with zero cross detection technique. This technique is based on the back EMF sensing and the commutation signals are generated by each zero crossing point of the terminal voltage. The gating signals are attained by switching sequence of BLDC motor and it is done by means of PI controller. The design analysis and simulation of the proposed system is done using MATLAB version $2010 \mathrm{~b}$ and the simulation results of sensored and sensorless method is compared.
\end{abstract}

Keywords---Brushless dc motor, sensorless control, zero cross detection, comparator.

\section{INTRODUCTION}

$I^{\mathrm{N}}$ $\mathrm{N}$ early years, numerous researches on sensorless control approaches for BLDC motor have been discussed in various fields. In [1] the author illustrates about the investigation, design and functioning of a high performance and cost effective sensorless method for BLDC Motors. It has some benefits such as removal of neutral voltage of the motor, eradication of fixed phase shift circuit, Low starting speed. The drawback is that the voltage spikes are produced by the residual current when the armature current is stopped up by power switches. The commutation fine-tuning and speeding

\footnotetext{
B. Tamilselvi, PG Scholar, Dept of Electrical \& Electronics Engineering, Sri Ramakrishna Engineering College, Coimbatore. E-mail: tamil.ciet@gmail.com

S.Mumtaj, Assistant Professor, Dept of Electrical \& Electronics Engineering, Sri Ramakrishna Engineering College, Coimbatore. E-mail: mumtaj.samsudheen@srecac.in
}

DOI: $10.9756 /$ BIJPSIC.4789 up of square wave winding current tracking response for sensor less BLDC motor is discussed in [2].

In [3] Low cost position sensorless control scheme is discussed for BLDC motor. Position of the rotor information is finding by circuitously sensing the back emf from any of the motor terminal voltages of 3 phase motor. The two classic control schemes [4] for BLDCM is square wave control scheme and the other is sinusoidal current control scheme.

The Sensorless control technique is highly dependable and reduced cost. In order to get an correct and ripple free instant torque of BLDC motor, the rotor position information should be known which can be attained by means of hall sensors scaled on a rotor are recommended in [5],[6]. The third harmonic back-EMF and phase-locked loop and for BLDC motor is discussed in [7]. The commutation drifts of the motor are away from the required phase angle owing to the transmission of the freewheel diode. As well, the drift angle and speed changes according to the motor factors and load conditions [8]. Access to the motor neutral point is mandatory, that will make difficult the motor design and increase the cost of overall system.

The majority of the sensorless speed control techniques are based on the back-EMF evaluation. However, when a motor is at stand still or very low speed, it is well known that the backEMF is too low to detect the specific rotor position. Therefore, a specific start-up method in sensorless drive system is needed. The common answer to the problem of open-loop start-up technique called $I-f$ starting method, where the current is specified and maintained constant during accelerating the motor, is proposed at the back-EMF based sensorless control of a permanent magnet synchronous motor [9]. Some drawbacks of the above mentioned sensorless and start-up technique are not applicable to some applications, which require the good reliability and various speed ranges with the high starting torque for the sensorless BLDC motor drive systems. To satisfy these requirements, this paper proposes a sensorless speed control using comparator with zero cross detection technique in BLDC motor.

\section{PRINCIPLES OF SENSORLESS BLDC MOTOR CONTROL}

Brushless DC motor drives have need of rotor position information for appropriate operation to execute phase commutation. Position sensors are generally used to provide the position information for the driver. So this type of position sensors is not used in sensorless drives. The advantage of 
sensorless drives comprises of less hardware cost, increased system reliability, decreased system size and reduced feedback units. And also they are free from mechanical and environmental constraints [10].

Various control methods, in which a back-EMF and current sensing, sufficient position information is provided for calculation with sufficient rotor position to drive the motor with synchronous phase currents. BLDC motor drives that do not require position sensors but it contains electrical dimensions are called a sensorless drive. The BLDC motor provides sensorless operation based on the nature of its excitation intrinsically suggest a low-cost way to take out rotor position information from motor-terminal voltages. In the excitation of a 3 phase BLDC motor, apart from the phasecommutation periods, two of the three phase windings are functioning at a time and no conducting phase carries in the back-EMF as shown in figure 1.

In BLDC motor the stator iron has a non-linear magnetic saturation features that is the fundamental from which it is feasible to find out the initial position of the rotor. When a stator winding is energized, then DC voltage is applied for a particular time and a magnetic field with a fixed direction will be recognized. Then, the stator current responses are changed owing to the inductance variation and this variation of the stator current responses which comprises of the information of the rotor position.

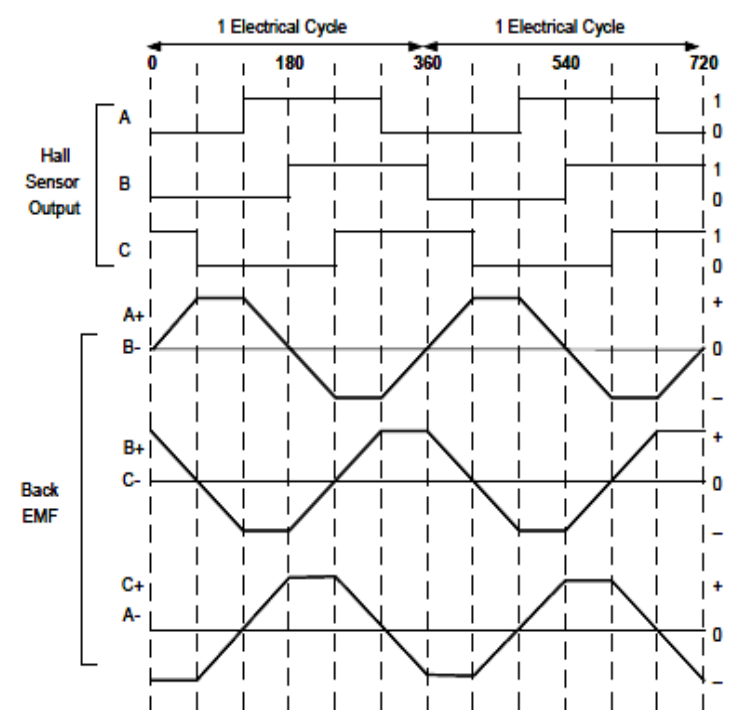

Figure 1: Hall sensor signals, back emf

\section{A. Back-EMF Zero Crossing Detection method}

The zero-crossing detection method is a easiest methods of back-EMF sensing approach and it is based on finding the instantaneous at which unexcited phase crosses zero due to back-EMF [11, 14]. This zero crossing activates a timer that might be as easy as an RC time constant; accordingly the next sequential inverter commutation take place at the end of timing interval.

For a distinctive operation of a BLDC motor, the backEMF and phase current should be associated to generate constant torque. Figure 2 shows the waveform for current commutation point which can be attained by the zero crossing point of back-EMFs and a six-step inverter commutation design for driving the BLDC motor [12, 15]. As a result the interval for every phase of a BLDC motor is conducted at 120 electrical degrees. Hence, in BLDC motor only two phases conduct current at whichever time. The third phase is called floating phase. In order to produce greatest torque, the inverter is to be commutated at every $60^{\circ}$ by calculating zero crossing of back-EMF on the floating phase of the motor, therefore the current is in phase with the back-EMF.

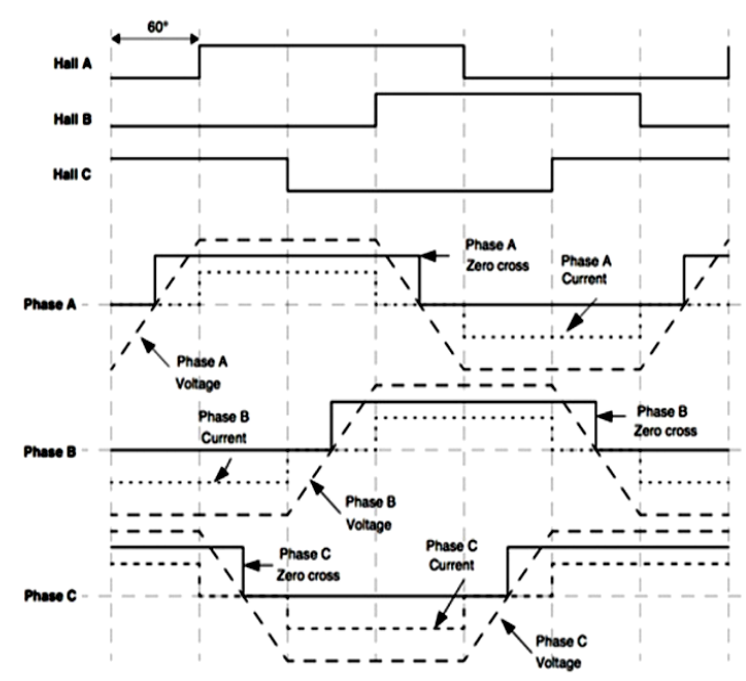

Figure 2: Waveforms of back emf and phase current

\section{Mathematical Model of BLDC Motor}

BLDC motor modelling is similar to three-phase synchronous machine modelling. The model is developed, in which the permanent magnet enclosed with the rotor and it contains different dynamic characteristics. Figure 3 shows the Inverter BLDC motor-drive model. The BLDC motor is fed to a three-phase voltage source is not necessary to be sinusoidal or square wave can be applied. The peak voltage produced over there should not exceed the maximum voltage of the motor.

The fundamental model of the armature winding for the BLDC motor is defined as [13],

$$
\begin{aligned}
& V_{a}=R i_{a}+L \frac{d i_{a}}{d t}+e_{a} \\
& V_{b}=R i_{b}+L \frac{d i_{b}}{d t}+e_{b} \\
& V_{c}=R i_{c}+L \frac{d i_{c}}{d t}+e_{c}
\end{aligned}
$$

Where

$\mathrm{L}$ is armature self inductance $[\mathrm{H}]$,

$\mathrm{R}$ is armature resistance $[\Omega]$,

$\mathrm{V}_{\mathrm{a}}, V_{b}, \mathrm{~V}_{\mathrm{c}}$ are terminal phase voltage [V],

$i_{\mathrm{a}}, i_{\mathrm{b}}, i_{\mathrm{c}}$ are motor input current [A], and $e_{\mathrm{a}}, e_{\mathrm{b}}, e_{\mathrm{c}}$ are motor back emf [V].

Therefore the circuit equations of the three windings in phase variables are, 


$$
\begin{gathered}
{\left[\begin{array}{l}
V_{a} \\
V_{b} \\
V_{c}
\end{array}\right]=\left[\begin{array}{lll}
R & 0 & 0 \\
0 & R & 0 \\
0 & 0 & R
\end{array}\right]\left[\begin{array}{l}
i_{a} \\
i_{b} \\
i_{c}
\end{array}\right]+\left[\begin{array}{ccc}
L_{a} & L_{b a} & L_{c a} \\
L_{b a} & L_{b} & L_{c a} \\
L_{c a} & L_{c b} & L_{c}
\end{array}\right] p\left[\begin{array}{l}
i_{a} \\
i_{b} \\
i_{c}
\end{array}\right]} \\
+\left[\begin{array}{l}
e_{a} \\
e_{b} \\
e_{c}
\end{array}\right]
\end{gathered}
$$

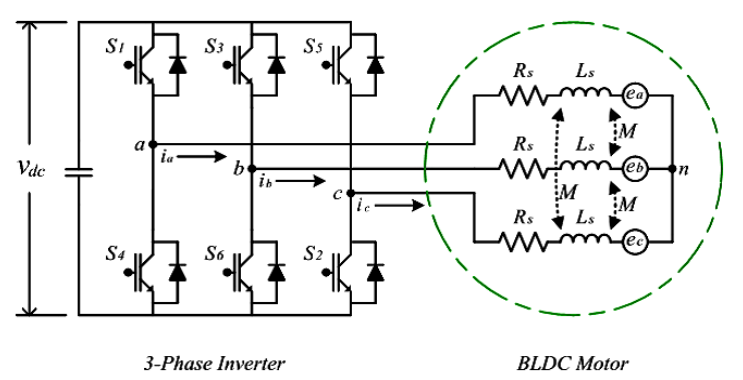

Figure 3: Inverter BLDC motor-drive model

As it has been considered that the stator resistances of all the windings are equivalent. The back emf such as $e_{\mathrm{a}}, e_{\mathrm{b}}$ and $e_{\mathrm{c}}$ have a trapezoidal shape. Assuming that there is no change in the rotor reluctance with angle, then

$$
\begin{gathered}
\mathrm{L}_{\mathrm{a}}=\mathrm{L}_{\mathrm{b}}=\mathrm{L}_{\mathrm{c}}=\mathrm{L} \\
\mathrm{L}_{\mathrm{ab}}=\mathrm{L}_{\mathrm{bc}}=\mathrm{L}_{\mathrm{ca}}=\mathrm{M} \\
{\left[\begin{array}{l}
V_{a} \\
V_{b} \\
V_{c}
\end{array}\right]=\left[\begin{array}{lll}
R & 0 & 0 \\
0 & R & 0 \\
0 & 0 & R
\end{array}\right]\left[\begin{array}{l}
i_{a} \\
i_{b} \\
i_{c}
\end{array}\right]+\left[\begin{array}{ccc}
L & M & M \\
M & L & M \\
M & M & L
\end{array}\right] p\left[\begin{array}{l}
i_{a} \\
i_{b} \\
i_{c}
\end{array}\right]+\left[\begin{array}{l}
e_{a} \\
e_{b} \\
e_{c}
\end{array}\right]}
\end{gathered}
$$

But

$$
\begin{gathered}
\mathrm{i}_{\mathrm{a}}+\mathrm{i}_{\mathrm{b}}+\mathrm{i}_{\mathrm{c}} \\
{\left[\begin{array}{l}
V_{a} \\
V_{b} \\
V_{c}
\end{array}\right]=\left[\begin{array}{lll}
R & 0 & 0 \\
0 & R & 0 \\
0 & 0 & R
\end{array}\right]\left[\begin{array}{l}
i_{a} \\
i_{b} \\
i_{c}
\end{array}\right]+\left[\begin{array}{ccc}
L-M & 0 & 0 \\
0 & L-M & 0 \\
0 & 0 & L-M
\end{array}\right] P\left[\begin{array}{l}
i_{a} \\
i_{b} \\
i_{c}
\end{array}\right]} \\
+\left[\begin{array}{l}
e_{a} \\
e_{b} \\
e_{c}
\end{array}\right]
\end{gathered}
$$

The electromagnetic torque is given by,

$$
\begin{aligned}
T_{e}= & \left(e_{a} i_{a}+e_{b} i_{b}+e_{c} i_{c}\right) / \omega_{r} \\
\mathrm{~T}_{\mathrm{e}}=\mathrm{K}_{\mathrm{t}} \mathrm{I} &
\end{aligned}
$$

The equation of a motor for a simple system with inertia $\mathbf{J}$, friction co-efficient $\mathrm{B}$ and load torque $\mathrm{T}_{1}$ is given by,

$$
\mathrm{T}_{\mathrm{e}}-\mathrm{T}_{\mathrm{l}}=\mathrm{Jd} \omega_{\mathrm{m}} / \mathrm{dt}+\mathrm{B} \omega_{\mathrm{m}}
$$

The output power is given by,

$$
\mathrm{p}=\mathrm{T}_{\mathrm{e}} \mathrm{\omega}
$$

The parameters R, B, J are influence the speed response of the Brushless DC motor.

\section{PRoposed SENSORLESS CONTROL USING COMPARATOR WITH ZERO CROSS DETECTION TECHNIQUE}

\section{A. Back EMF Sensing}

The comparator with zero cross detection technique is achieved by sensing the back EMF. The back EMF sensing is based on the information that only two phases of a BLDC motor are connected at a time and the third phase is presented to note the back EMF voltage. Consider phase $\mathrm{C}$ as floating for a particular step,

$$
U_{C}=U_{I c}+U_{n}
$$

Where

$\mathrm{U}_{\mathrm{C}}$ is the terminal voltage of the phase $\mathrm{C}$,

$\mathrm{U}_{\mathrm{Ic}}$ is the phase back emf and

$\mathrm{U}_{\mathrm{n}}$ is the neutral voltage of the motor.

From phase A, the term for neutral voltage is expressed as,

$$
U_{n}=V_{d c}-V_{M O S}-R_{i}-L \frac{d i}{d t}-U_{I a}
$$

From phase B, the equation turns out to be,

$$
U_{n}=V_{M O S}+R_{i}+L \frac{d i}{d t}-U_{I b}
$$

Where

$\mathrm{V}_{\text {MOS }}$ is the voltage drop on MOSFET.

From equation (12) and (13),

$$
U_{n}=\frac{V_{d c}}{2}-\frac{\left(U_{I a}+U_{I b}\right)}{2}
$$

Considering a three-phase system by neglecting the third harmonics, the equation would be discussed below

$$
U_{I a}+U_{I b}+U_{I c}=0
$$

From equation (14) and (15),

$$
U_{n}=\frac{V_{d c}}{2}-\frac{\left(U_{I c}\right)}{2}
$$

and the terminal voltage $\mathrm{U}_{\mathrm{c}}$,

$$
U_{c}=U_{I c}+U_{n}=\frac{3 U_{I c}}{2}+\frac{V_{d c}}{2}
$$

From equation (11) to (17), it is to be noted that the terminal voltage of the floating phase of PWM is directly proportional to the back EMF voltage plus the half of dc bus voltage.

\section{B. Comparator with Zero Cross Detection technique}

In proposed method the comparators are used for generating the gating signals, by comparing $U_{a}, U_{b}$, and $U_{c}$ to $U_{n}$. If $U_{a}$ is greater than $U_{n}$, then the comparator outputs high level, else the comparator outputs low level, which is expressed as $Z_{a}$ as shown in figure 4 . At the rising edge of $Z_{a}$, the MOSFET $\mathrm{Q}_{1}$ should be ON, and the MOSFET $\mathrm{Q}_{5}$ should be OFF, at the falling edge of $Z_{a}$, the MOSFET $\mathrm{Q}_{4}$ should be $\mathrm{ON}$, and the MOSFET $\mathrm{Q}_{2}$ should be OFF. Similarly, according to the rising and falling edge of $Z_{b}$ and $Z_{c}$, the other commutation instants should be obtained. The gating signals generated from the every commutation instants $Z_{a}, Z_{b}$, and $Z_{c}$. 
Consequently, the BLDC motor could work normally on the prior state which is obtained from the switching table.

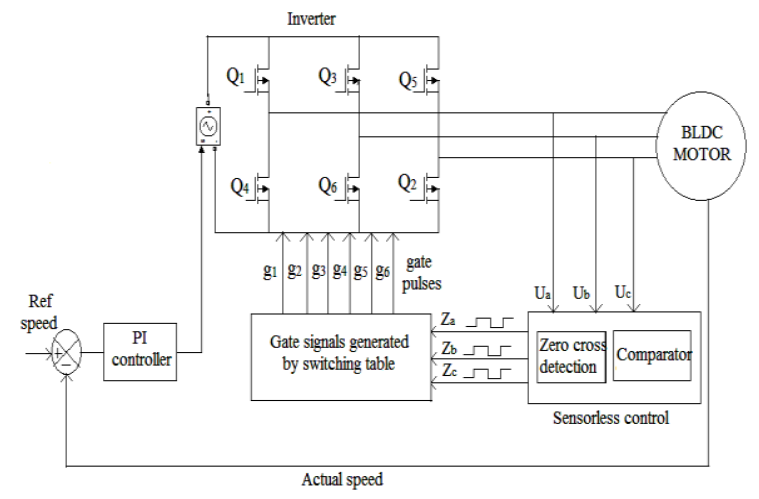

Figure 4: Block diagram of Sensorless speed control of Brushless DC motor

\section{Simulation Results AND Discussion}

The experimental analysis is conducted in MATLAB 7.0. Simulation studies were carried out to evaluate the performance of both sensorless and sensor based speed control of BLDC motor. The output waveform of back emf, stator current and zero crossing point of back emf as shown in figure 5, 6 and 7. The speed responses under various speed ranges were observed. The comparative result shown in figure 8 and 9 that the speed of the BLDC motor can be controlled with out sensors and the values are same as with sensors. So the performance of BLDC motor is same in both sensors and sensorless method. It can be seen that there are no overshoots in various speed in the PI as it is well tuned for sensorless control of BLDC motor for various speed control applications.
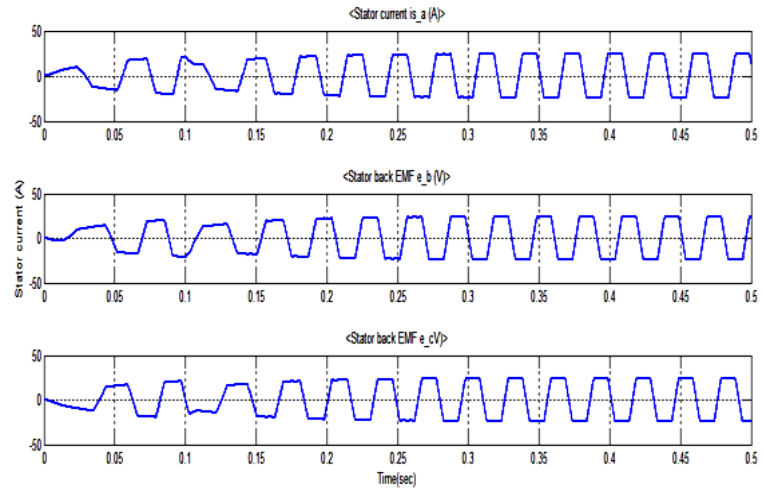

Figure 5: Output waveform of back emf

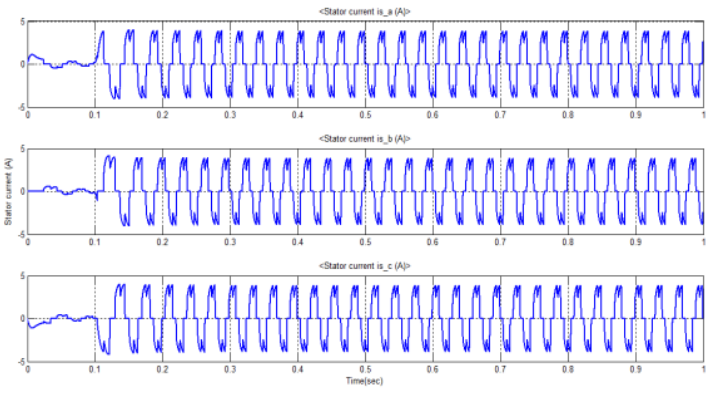

Figure 6: Output waveform of stator current
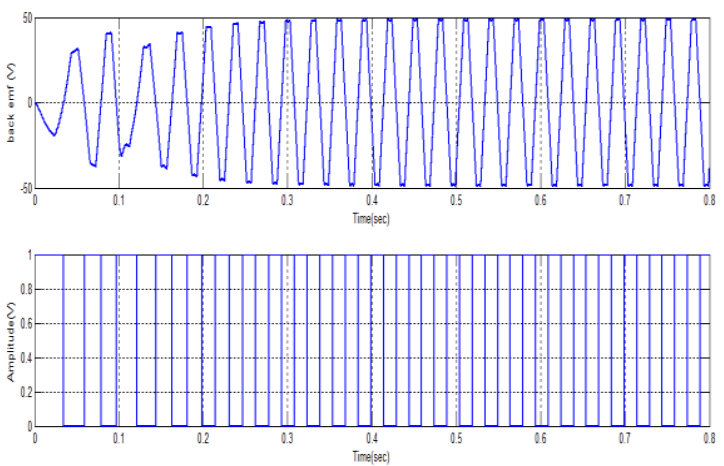

Figure 7: output waveform of zero crossing point

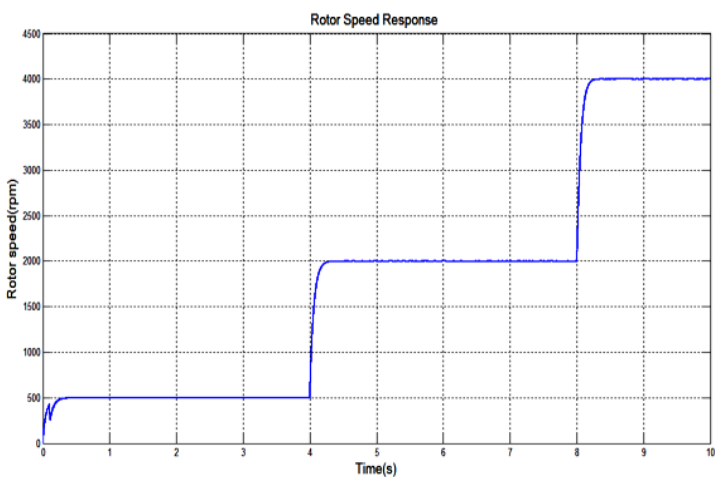

Figure 8: Sensor based speed control of BLDC motor with various speed

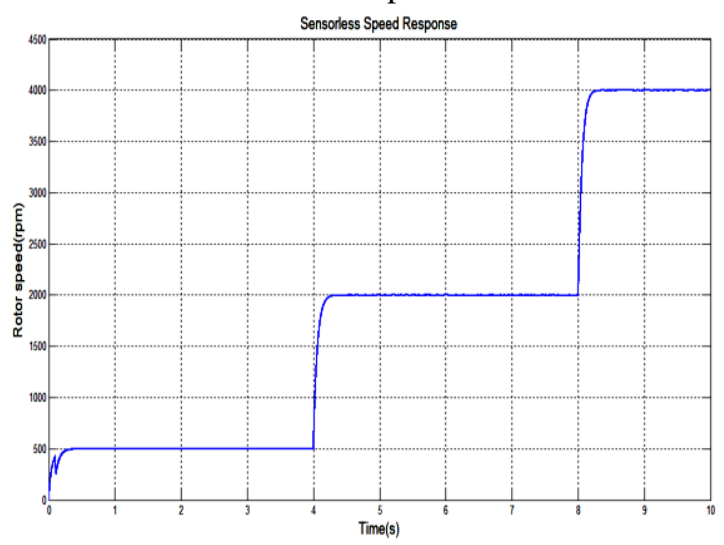

Figure 9: Sensorless speed control of BLDC motor with various speed

\section{CONCLUSION}

Sensorless control of BLDC motor drive based on comparator with zero cross detection with PI controller have been experimented using MATLAB and the evaluation of the results are observed. The simulated results have shown that the various speed of the BLDC motor can be controlled without sensors and the values are remain the same as that with the sensors. The results obtained from sensorless speed control of BLDC motor demonstrate that the system is less cost compared to sensored control and also good dynamic performance is obtained. Obtained results confirm the effectiveness of the proposed system under various speed ranges. This makes the motor suitable in applications such as fuel pump, robotics and industrial automation etc. The 
proposed speed control scheme is robust, efficient and easy to implement.

\section{REFERENCES}

[1] P. P. Carney and J. F Watson, "Review of position-sensor less operation of permanent-magnet machines," IEEE Trans. Ind. Electron., vol. 53, no. 2, pp. 352-362, Apr. 2006.

[2] C.-H. Chen and M.-Y. Cheng, "New cost effective sensor less commutation method for brushless dc motors without phase shift circuit and neutral voltage," IEEE Trans. Power Electron., vol. 22, no. 2, pp. 644-653, Mar.2007

[3] C.-G. Kim, J.-H. Lee, H.-W. Kim, and M.-J. You, "Study on maximum torque generation for sensor less controlled brushless DC motor with trapezoidal back EMF," IEE Proc.-Electro. Power Appl., vol. 152, no. 2, pp. 277-291, Mar. 2005

[4] J.X. She and S. Iwasaki, "Sensor less control of ultrahigh-speed PM brushless motor using PLL and third harmonic back EMF," IEEE Trans. Ind. Electron., vol. 53, no. 2, pp. 421-428, Apr. 2006.

[5] J. Shao, (2006) 'An improved microprocessor-based sensorless brushless DC(BLDC) motor drive for automotive applications', IEEE Trans. Ind. Appl.,Vol.42, No.5, pp.1216-1211.

[6] J. Gao and Y. Hu, (2010) 'Direct self control for BLDC motor drives based on three-dimensional coordinate system', IEEE Trans. Ind. Electron.,Vol.57, No.8, pp.2836.

[7] J.X. Shen, and Z. Q. Zhu and D. Howe, (2004) 'Sensorless flux weakening control of permanent-magnet brushless machines using thirdharmonic back-EMF', IEEE Trans .Ind. Appl.,Vol.40, No.6, pp.16291636.

[8] J. X. Shen and S. Iwasaki,(2006) 'Sensorless control of ultra high-speed PM brushless motor using PLL and third harmonic back-EMF', IEEE Trans. Ind. Electron.,Vol.53, No.2, pp.421-427.

[9] Z. Wang, K. Lu, and F.Blaabjerg, (2012) 'A simple startup strategy based on current regulation for back-EMF-based sensorless control of PMSM', IEEE Trans. Power Electron., Vol.27,. No.8, pp. 3817-3825.

[10] José Carlos Gamazo-Real, Ernesto Vázquez-Sánchez, and Jaime Gómez-Gil, "Position and Speed Control of Brushless DC Motors Using Sensorless Techniques and Application Trends", 2010.

[11] J.Shao, D.Nolan, and T.Hopkins, "A Novel Direct Back EMF Detection for Sensorless Brushless DC (BLDC) Motor Drives," Applied Power Electronic Conference (APEC 2002), pp33-38.

[12] Jiang Q, Bi C, Huang R. A New Phase-Delay-Free Method to Detect Back EMF Zero-Crossing Points for Sensorless Control of Spindle Motors. IEEE Trans. Magn. 2005;41:2287-2294.

[13] S. Poonsawat, and T. Kulworawanichpong, Speed Regulation of a Small BLDC Motor using Genetic-Based Proportional Control", World Academy of Science, Engineering and Technology 472008.

[14] P. Damodharan, Krishna Vasudevan, " Sensorless brushless DC motor drive based on the zero crossing detection of back EMF from the line voltage difference" IEEE September 2010

[15] John-Sheok Kim, Seung-Ki Sul, "New Approach for High-Performance PMBLDC Drives without Rotational Position Sensors" IEEE September 1997 